\title{
Induction of double flowers in Pharbitis nil using a class-C MADS- box transcription factor with Chimeric REpressor gene-Silencing Technology
}

\author{
Kimiyo Sage-Ono ${ }^{1}$, Yuko Ozeki ${ }^{1}$, Satomi Hiyama ${ }^{1}$, Yohei Higuchi ${ }^{2}$, Hiroshi Kamada ${ }^{1}$, \\ Nobutaka Mitsuda ${ }^{3}$, Masaru Ohme-Takagi ${ }^{3}$, Michiyuki Ono $^{1, *}$ \\ ${ }^{1}$ Gene Research Center, Graduate School of Life and Environmental Sciences, University of Tsukuba, Tsukuba, Ibaraki \\ 305-8572, Japan; ${ }^{2}$ National Institute of Floricultural Science, National Agriculture and Food Research Organization, \\ Tsukuba, Ibaraki 305-8519, Japan; ${ }^{3}$ Research Institute of Genome-Based Biofactory, National Institute of Advanced \\ Industrial Science and Technology (AIST), Tsukuba, Ibaraki 305-8562, Japan \\ *E-mail: ono.michiyuki.fm@u.tsukuba.ac.jpＴel: +81-29-853-7759 Fax: +81-29-853-7746
}

Received November 1, 2010; accepted January 19, 2011 (Edited by N. Ohtsubo)

\begin{abstract}
The Chimeric REpressor gene-Silencing Technology (CRES-T) system is a novel reverse genetic method using a chimeric transcriptional repressor fusing an EAR transcriptional repression domain called SRDX. We sought to change the flower shape of Pharbitis nil, a model ornamental flower, using an Arabidopsis transcription factor fused with SRDX. For the first trial modulating flower shape we transformed with the class-C MADS-box transcription factor AGAMOUS (AG) fused with SRDX (AGSRDX). Defects in class-C genes cause double flowers in Arabidopsis and Pharbitis. However, when AGSRDX was expressed under the CaMV 35S promoter ( $35 S)$, the transgenic Pharbitis bore a malformed flower with a protruding pistil. We then used DUPLICATED $(D P)$, one of the class-C genes in Pharbitis. The p35S::DPSRDXintroduced callus were difficult to regenerate during transgenic steps, but occasionally made a perfect double flower bud showing severe growth defects. The flower buds never developed to flower opening stage. These results indicate that CRES$\mathrm{T}$ is functional in Pharbitis but even using a conserved transcription factor, some species-specific variation might exist. To avoid these unwanted effects, we recruited inducible promoters to control expression of the chimeric transcription repressors in combination with the DNA-binding domain of GAL4 in yeast fused with SRDX and the GAL4 upstream activator sequence (UAS). Normal regeneration was observed by inducible repression of DPSRDX during in vitro redifferentiation, and the double-flowered Pharbitis was generated. We successfully induced a non-transformant (NT)-like flower in DPSRDX-expressing double-flowered transformants. Our approach will enable us to breed transgenic horticultural plants with inducible fertility.
\end{abstract}

Key words: Chimeric repressor, CRES-T, double flower, inducible promoter, Pharbitis nil.

In higher plants, adjustment of development, differentiation, and responses to the environment are controlled strictly by transcription factors, which often form large gene families in which family members include strongly conserved DNA-binding domains (Riechmann et al. 2000). This structural redundancy obstructs the functional analysis of plant transcription factors. Even if the expression of one transcription factor is controlled, that influence is not often shown in the plant phenotype. To solve this problem, Takagi's group developed a novel gene silencing technology, called CRES-T (Chimeric REpressor gene-Silencing Technology), in which a chimeric repressor is produced by fusion of a transcription factor to the plant-specific ETHYLENE-RESPONSIVE

ELEMENT-BINDING FACTOR (ERF)-associated amphiphilic repression
(EAR)-like motif repression domain (Hiratsu et al. 2002; Ohta et al. 2001). The repression domains of ERF and TFIIIA-type zinc finger repressors of transcription that include SUPERMAN (SUP) (Bowman et al. 1992) contain the EAR motif (Hiratsu et al. 2002; Ohta et al. 2001). The EAR motif is able to convert a transcriptional activator into a strong repressor, and the repressive activity of the EAR motif repression domain is dominant over both intra- and intermolecular activational activities (Hiratsu et al. 2002; Ohta et al. 2001). The chimeric repressors derived from various transcription factors dominantly suppress the expression of the respective target genes, and the resultant transgenic plants exhibit loss-of-function phenotypes specific for the target genes at high frequency (Fujita et al. 2005; Hiratsu et al. 2003; Iida et al. 2007; Ikeda et al. 2009; Koyama et al. 2007; 
Matsui et al. 2004, 2005; Mitsuda et al. 2005, 2006; Tohge et al. 2005).

Mutant analyses of Arabidopsis thaliana and Antirrhinum majus have revealed that a number of genes that regulate flower development encode transcription factors. These transcription factors are categorized into $\mathrm{ABC}$ genes, which specify floral organ identity (Bowman et al. 1989; Coen and Meyerowitz 1991; Coen et al. 1990; Goto and Meyerowitz 1994; Jack et al. 1994; Mandel et al. 1992; Yanofsky et al. 1990). Most ABC genes encode MADS-box transcription factors. One of the most striking phenotype is the mutation of the AGAMOUS ( $A G$ ) gene in Arabidopsis. Stamens of the ag mutant are converted into petals, and the fourth whorl bears another $a g$ flower, resulting in an indeterminate flower with a repetitive pattern of sepals, petals and petals (Yanofsky et al. 1990).

In this report, we describe the application of CRES-T to the Arabidopsis transcription factor $A G$ (Yanofsky et al. 1990) and its homologue in Pharbitis, namely DUPLICATED (DP) (Nitasaka 2003), which are involved in the regulation of stamen and carpel identity, with the objective of generating new traits in horticultural plants. Pharbitis nil (Ipomoea nil [L.] Roth), the Japanese morning glory, was first introduced into Japan from China during the Nara era (710-794) and has long been cultivated as a horticultural plant. Most of the existing mutants were selected during the late Edo era (1603-1868), and these mutant lines are still maintained. Japanese geneticists analyzed some of these mutants in the 1910s (Imai 1930, 1938). Based on recent molecular studies of these mutations, most are thought to be induced by Enhancer/Suppressor-mutator (En/Spm)related transposable elements of the Tpn1 (transposable element from Pharbitis nil 1) family (Iida et al. 1999, 2004). In a $d p$ mutant, an $\mathrm{E}_{\mathrm{n}} / \mathrm{Spm}$-related transposable element of $P$. nil (Tpn-botan) was inserted in the second intron of DP (Nitasaka 2003). Mutants of this species exhibit particularly rich and varied floral colors, patterns and floral form compared to other model plants.

Although $P$. nil is a typical short-day plant, cv. Violet is an especially sensitive genotype and can be induced to flower by a single 16-h exposure to continuous darkness, whereas plants of $\mathrm{cv}$. Violet grown under continuous light cannot be induced to flower (Imamura 1967; VincePrue and Gressel 1985). Therefore P. nil cv. Violet has been used as a model plant for studies of floral color, floral form and photoperiodic induction of flowering. Previously, we reported a reliable transformation protocol mediated by Agrobacterium tumefaciens containing virGN54D, called a 'ternary system', and plant regeneration for $P$. nil cv. Violet (Kikuchi et al. 2005).

CRES-T system is a powerful tool for genetic recombination in plants and the Cauliflower mosaic virus
(CaMV) 35S promoter-driven chimeric repressor dominantly suppresses the target genes. However, in some cases, growth defects and decreased fertility are observed. Thus, we developed new technology to control the expression of the transgene, with the aim of realizing genetic recombination of floricultural plants. The GAL4DB transcription factor of yeast was used, and vectors in which GALADBSRDX were expressed by inducible promoters were constructed. The GALADBSRDX was originally developed to compare the strength of repression motifs and was used only for transient gene expression assay (Hiratsu et al. 2004). We applied this GALADBSRDX for controlling gene expression in stable transformants as the key component, and developed the GAL4SRDX/UAS system driven by inducible promoters (alcohol-inducible and heat-shock promoters) represses the overexpression of the transgene under the control of $35 \mathrm{~S}$ promoter : GAL4UAS.

The Alc gene expression system, which is based on a regulon from Aspergillus nidulans (Felenbok et al. 1988; Pateman et al. 1983; Sealy-Lewis and Lockington 1984), and the heat-shock inducible promoter (Matsuhara et al. 2000; Takahashi et al. 1992) were used as inducible promoters. The alcR transcriptional regulator is expressed with the CaMV35S promoter such that, in the presence of ethanol, ALCR induces expression of any gene fused to a modified alcR promoter (Caddick et al. 1998). On the other hand, the heat-shock inducible promoter HSP18.2 from Arabidopsis, encoding a heatshock protein, is indicated to function as a strong inducible system in plants (Takahashi et al. 1992; Matsuhara et al. 2000). These inducible promoters have been used to construct controllable gene expression systems in plant cells. In this report, we describe the construction and phenotype of transgenic Pharbitis using a CRES-T system and the application in combination of these inducible promoters. It is expected that utilization of the GAL4SRDX/UAS system driven by inducible promoters (alcohol-inducible and heat-shock promoters) could be applied for genetic engineering of horticultural plants because GAL4SRDX could repress the growth defects and decreased fertility caused by an ectopic overexpressing transgene.

\section{Materials and methods}

\section{Plant materials and growth conditions}

Seeds of Pharbitis nil cv. Violet (Marutane Co., Kyoto, Japan) and a $d p-1$ mutant Q0426 (kindly provide by Dr. Nitasaka) were germinated on wet vermiculite. Seedlings were grown at $24 \pm 1{ }^{\circ} \mathrm{C}$ with illumination by continuous cool-white fluorescent light $\left(60 \mathrm{mmol} \mathrm{m}^{-2} \mathrm{~s}^{-1}\right.$, FL 40SS W/37 lamps; Matsushita Electronics Co., Tokyo, Japan). 


\section{Construction of plasmids for chimeric repressor- overexpressor}

The AGSRDX-overexpressor construct ( $p B C K K-35 S-A G-R D$ ) was used (Mitsuda et al. 2006). To construct the chimeric repressor, DPSRDX, the coding sequence of DUPLICATED $(D P)$ (AB006182) cDNA, excluding the stop codon, was amplified from a Pharbitis apical bud cDNA. The amplified fragment was cloned into the SmaI site of the p35SSRDXG vector, in frame to the region that encodes the SRDX repression domain (LDLDLELRLGFA) from SUPERMAN (Hiratsu et al. 2002, 2003, 2004). The p35SSRDXG vector contains a CaMV $35 \mathrm{~S}$ promoter followed by an $\Omega$ translation enhancer sequence, the SRDX repression domain sequence, NOS terminator, and the attL1 and attL2 Gateway recombination sites (Invitrogen Corp., Carlsbad, CA, USA) outside the regions of the $35 \mathrm{~S}$ promoter and the nopaline synthase (NOS) terminator in the pUC119 vector. The transgene cassette was transferred into the destination vector $p B C K K$ (Fujita et al. 2005) using the Gateway LR clonase reaction (Invitrogen). The $p B C K K-35 S-D P-R D$ construct was formed from a destination vector, $p B C K K$, and an entry clone, $p 35 S-D P-R D$, using the Gateway LR clonase reaction (Invitrogen).

\section{Reverse transcriptase-polymerase chain reaction}

To investigate the expression profiles in NT plants and mRNA accumulation in transformants, total RNAs were isolated using the Get Pure RNA Kit (Dojindo, Kumamoto, Japan). Firststrand cDNA was synthesized from $1 \mu \mathrm{g}$ of each RNA sample in a $20 \mu$ reaction solution using a Super Script ${ }^{\circledR}$ First-Strand Synthesis System (Invitrogen) according to the manufacturer's instructions. Reactions were carried out on a thermal cycler, starting denaturation at $94^{\circ} \mathrm{C}$ for 2 min followed by 35 cycles at $94^{\circ} \mathrm{C}$ for $30 \mathrm{~s}, 55^{\circ} \mathrm{C}$ for $30 \mathrm{~s}$ and $72^{\circ} \mathrm{C}$ for $30 \mathrm{~s}$. The $P n U B Q$ gene was used as an internal standard. The primers used in this experiment are listed in Supplemental Table 1. The PCR products were separated on $1.5 \%$ agarose gels.

\section{Construction of plasmid for inducible repression vectors}

Inducible repression vectors using GAL4SRDX and GAL4UAS transcription systems were constructed with the MultiSite Gateway ${ }^{\circledR}$ Three-Fragment Vector Construction Kit (Invitrogen). The combined genetic elements p35S-GAL4UAS (in pDONR ${ }^{\mathrm{TM}}$ 221-P4-P1r; between B4 and B1 in Figure 3C), DPSRDX or LUCIFERASE (Luc) (in pENTR-D-TOPO; between $\mathrm{B} 1$ and $\mathrm{B} 2$ in Figure 3C), and 35S-T-NOS-T-
GAL4SRDX-inducible promoter, Alc promoter system (p35S::alcR and AlcA promoter from binSRNACatN [pALC] or HSP18.2 promoter from pTT101 [pHSP]) (in pDONR-P2r$\mathrm{P} 3$; between $\mathrm{B} 2$ and $\mathrm{B} 3$ in Figure $3 \mathrm{C}$ ) were merged and introduced via a MultiSite LR clonase reaction into a destination vector (pKm43GW) (Karimi et al. 2005) carrying the attR4-ccdB-attR3 Gateway cassette, yielding the expression clones $p K m A G D$ ( $p A L C: \because G A L 4 S R D X$; $35 S: G A L 4 U A S::$ DPSRDX), pKmHGD (pHSP::GAL4SRDX;p35S:GAL4UAS:: DPSRDX), pKmAGL (pALC::GAL4SRDX;p35S:GAL4UAS:: Luc) and pKmHGL (pHSP::GAL4SRDX; p35S:GAL4UAS:: $L u c)$, respectively.

The coding sequence of $D P$ and $L u c$, excluding the stop codon, were amplified from each cDNA clone, and cloned into the entry vector $\mathrm{pENTR/D-TOPO}$ (Invitrogen). The genetic element $p 35 S-G A L 4 U A S$ was amplified from $p 35 S$ : GAL4UASTATA-LUC vector using the attB4-flanked primer, 5'GGGGACTGCTTTTTTGTACAAACTTGGATCTAGTAACA TAGATGACACCGC-3' and the attB1r-flanked primer, 5'GGGGACTGCTTTTTTGTACAAACTTGGGTCGACTGTAA TTGTAAATAGTAATTG-3', and cloned into pDONR ${ }^{\mathrm{TM}} 221$ P4-P1r (Invitrogen) by BP clonase ${ }^{\mathrm{TM}}$ (Invitrogen). To combine the genetic fragments of $35 S-T$, GAL4SRDX-NOS-T, Alc promoter system (pALC) or the heat-shock promoter (pHSP), the overlapping sequences were included in the oligonucleotides carrying the $5^{\prime}$ and $3^{\prime}$ gene-specific sequences designed for PCR amplification of the corresponding fragments. The genetic element 35S-T-NOS-T-GAL4SRDXinducible promoter (Alc promoter system [pALC] or HSP18.2 promoter [pHSP]) was amplified from the combined PCR products using the attB2r-flanked primer, 5'GGGGACAGCTTTCTTGTACAAAAGTGGGGTCACTGGA TTTTGGTTTTAGG-3' (for Alc and heat-shock promoters) and attB3-flanked primers, 5'-GGGGACAACTTTGTATAATAAAGTTGAATTCCCATGGAGTCAAAGATTC-3' (for Alc promoter system), and 5'-GGGGACAACTTTGTATAATAAAGTTGTTCTCTTCATTTCTCTTTCTTTC-3' (for Heat-shock promoter), and cloned into $\mathrm{pDONR}^{\mathrm{TM}}$-221-P2r-P3 (Invitrogen) with BP clonase $^{\mathrm{TM}}$ (Invitrogen).

\section{Transformation of Pharbitis nil}

The pBCKK-35S-AG-RD, pBCKK-35S-DP-RD, pKmAGD, pKmHGD, pKmAGL and pKmHGL expression vectors were transformed into Pharbitis nil cv. Violet using A. tumefaciens strain LBA4404 (virG N54D) as previously described (Kikuchi et al. 2005).

Table 1. Plasmids used for transgenic Pharbitis in this study

\begin{tabular}{|c|c|c|}
\hline \multicolumn{2}{|c|}{ transgenic plants plasmid } & \multirow[b]{2}{*}{$p 35 S:: A G S R D X$} \\
\hline$p 35 S:: A G S R D X$ & pBCKK-35S-AGRD & \\
\hline$p 35 S:: D P S R D X$ & pBCKK-35S-DPRD & $p 35 S: \because D P S R D X$ \\
\hline$A G D$ & pKmAGD & 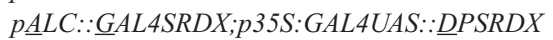 \\
\hline$A G L$ & pKmAGL & $p \underline{A} L C: \because \underline{G} A L 4 S R D X ; p 35 S: G A L 4 U A S:: \underline{L} u c$ \\
\hline$A L$ & pKmAL & $p \underline{\bar{A}} L C: \because \underline{\bar{L}} u c$ \\
\hline$H G D$ & pKmHGD & $p \underline{\bar{H}} S P:: \underline{\bar{G}} A L 4 S R D X ; p 35 S: G A L 4 U A S: \because \underline{D P S R D X}$ \\
\hline$H G L$ & pKmHGL & $p \underline{H} S P: \because \underline{G} A L 4 S R D X ; p 35 S: G A L 4 U A S:: \underline{L} u c$ \\
\hline$H L$ & $\mathrm{pKmHL}$ & $p \underline{H} S P: \because \underline{L} u c$ \\
\hline
\end{tabular}

pBCKK (Fujita et al. 2005); pKm: pKm43GW (Karimi et al. 2005); pALC: p35S::alcR and pAlcA from binSRNACatN (Caddick et al. 1998); pHSP: pHSP18.2 from pTT101 (Takahashi et al. 1992). 
A

\begin{tabular}{|l|l|l|l|l|}
\hline$p 35 S$ & $\Omega$ & $A G$ & SRDX & NOS-T \\
\hline
\end{tabular}

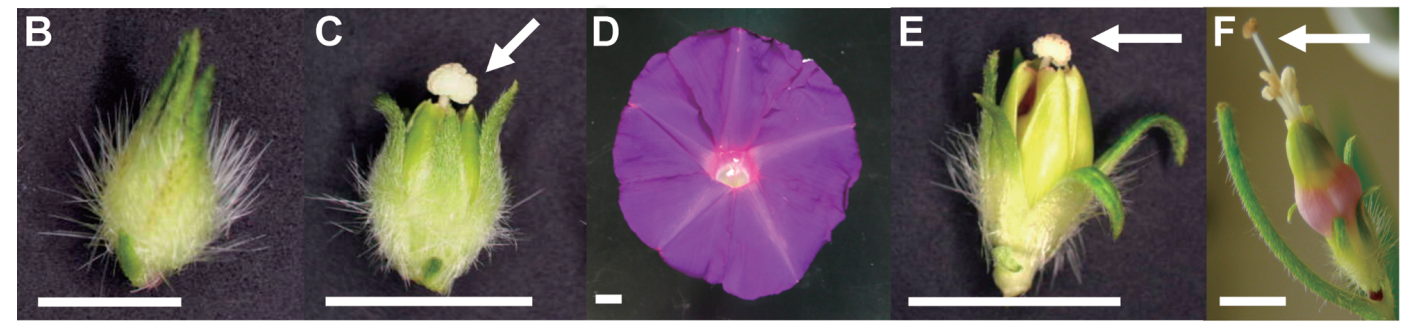

G

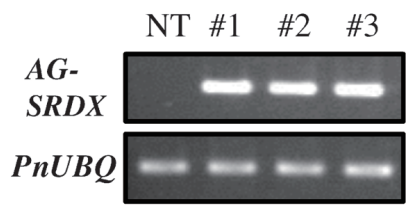

H

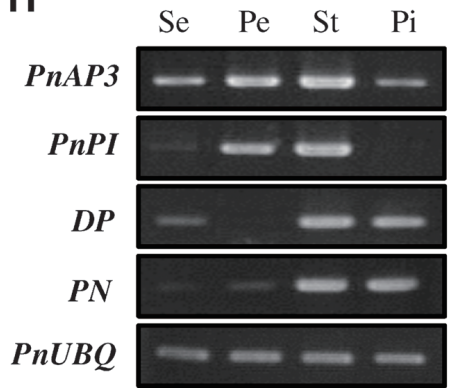

I

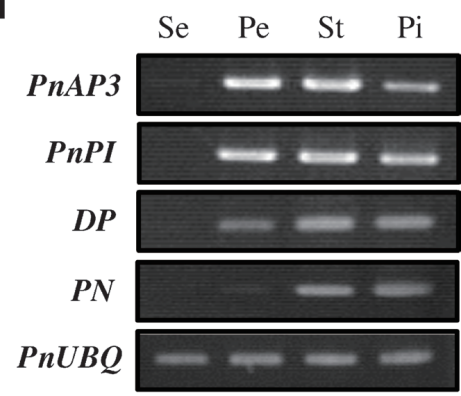

Figure 1. Functional analysis of $p 35 S:: A G S R D X$ in Pharbitis. (A) Schematic representation of the $p 35 S:: A G S R D X$ construct. 35Spro, $\Omega$, SRDX, and NOS-T represent the Cauliflower mosaic virus (CaMV) 35S promoter, the translational enhancer sequence from Tobacco mosaic virus, repression domain (LDLDLELRLGFA) from Arabidopsis SUPERMAN, and a nopaline synthase terminator, respectively. (B) A flower bud of non-transformant (NT) Pharbitis. (C) A flower bud of p35S::AGSRDX transformant. (D) A flower of NT Pharbitis. (E, F) The B-type mutant-like flower of $p 35 S: \because A G S R D X$. (E) Strong phenotype line of p35S::AGSRDX. (F) Weak phenotype line of $p 35 S: \because A G S R D X$. Arrows indicate a projecting pistil. (G-I) Expression analysis by reverse transcriptase-polymerase chain reaction (RT-PCR). $P n U B Q$ indicates expression of the gene for ubiquitin, used as an internal control. (G) The expression of $A G S R D X$ in NT and in three independent $\mathrm{T}_{1}$ transgenic lines (numbers indicated above gel). Total RNA was extracted from 1.5-cm-long young leaves of each plant. (H) Expression of PnAPETALA3 (PnAP3), PnPISTILLATA (PnPI), DP, and PN in NT tissues. Total RNA was extracted from floral organs (Se: sepal, Pe: petal, St: stamen, Pi: pistil). (I) Expression of $P n A P 3, P n P I, D P$, and $P N$ in $A G S R D X$. All scale bars represent $8 \mathrm{~mm}$.

\section{Ethanol induction}

In vitro cultured transgenic $\mathrm{T}_{1}$ shoots were treated with absolute ethanol vapor for $30 \mathrm{~min}$ in the plastic container every two weeks. For plants cultured in soil, ethanol treatment was performed by spraying $0.1 \%$ ethanol onto apical shoots, or the tip of the vine of mature plants was dipped into $1 \%(\mathrm{v} / \mathrm{v})$ ethanol solution.

\section{Heat-shock induction}

In vitro cultured transgenic $\mathrm{T}_{1}$ shoots were heat-shock-treated in a plant-growth chamber at $39^{\circ} \mathrm{C}$ for $2 \mathrm{~h}$ per day under longday (14 h light $/ 10 \mathrm{~h}$ dark) conditions. For plants cultured in soil, the heat-shock treatment was performed in a plant-growth chamber under identical conditions. These plants were cultured for one month.

\section{Results}

Expression of chimeric repressors derived from AG in Pharbitis resulted in a class-B mutant-like phenotype

In Arabidopsis, the phenotypes of transgenic plants under the control of the CaMV $35 \mathrm{~S}$ promoter (p35S::AGSRDX) were very similar to those of ag mutants (Mitsuda et al. 2006; Yanofsky et al. 1990). Flowers of the transgenic plants were composed of a repeated structure of sepals instead of functional stamens and carpel (Mitsuda et al. 2006). In the case of Pharbitis p35S::AGSRDX transgenic plants, 33\% of independent $\mathrm{T}_{1}$ transgenic lines ( 9 of 27 lines) were similar to the Arabidopsis weak apetala3 (ap3) mutant (a MADS-box class-B mutant; Jack et al. 1992), which had extra short green petals and a projecting pistil (Figure 1C, E, F) compared to non-transformant (NT) flowers (Figure 1B, D). Because these transgenic lines were male sterile, we could not obtain seeds. We confirmed the expression of $A G S R D X$ in all $27 p 35 S:: A G S R D X$ transgenic lines; expression in three independent $T_{1}$ transgenic lines is shown in Figure 1G. To quantify the mRNA of PnAP3 (an AP3 homologue), PnPI (a PISTILLATA homologue), $D P$ (an $A G$ homologue) and $P N$ (an $A G$ homologue), which are all homologues of MADS-box genes in Pharbitis nil, in floral organs of NT Pharbitis (Figure $1 \mathrm{H})$ and $p 35 S: \because A G S R D X$ transgenic Pharbitis (Figure 1I), mRNAs from each floral whorl were isolated and analyzed by RT-PCR. Figure $1 \mathrm{H}$ shows PnAP3 expression from whorl 1 (sepal: Se), whorl 2 (petal: Pe), 
whorl 3 (stamen: St), and whorl 4 (pistil: Pi). Transcripts of the two B-function genes PnPI and PnAP3 were detected mainly in whorl 2 and whorl 3 , but very weak expression in whorl 1 was also observed (Figure 1H). An identical result was observed for the tobacco MADS-box gene NTDEF (Davies et al. 1996), but this expression pattern differed from those of other B-function MADSbox genes, AP3, PI, DEFICIENS (DEF) and GLOBOSA (GLO) (Jack et al. 1992; Sommer et al. 1990; Trobner et al. 1992). In contrast, $D P$ transcripts were found mainly in whorl 3 and whorl 4. This expression pattern follows observations from other class-C MADS-box genes, $A G$ and $P L E$; their transcripts were only found in floral buds, but especially in whorl 3 and whorl 4 (Bradley et al. 1993; Yanofsky et al. 1990). However, weak expression of $D P$ and $P N$ transcripts were also observed in whorl 1 and whorl 2 (Figure 1H).

Ectopic over-expression of $A G S R D X$ resulted in repression of $P n A P 3$ expression in whorl 1, but enhanced $P n P I$ expression in whorl 4 and $D P$ expression in whorl 2 (Figure 1I). These results indicate that $A G$ acts as a Bfunction gene in Pharbitis, and in some cases the function of the chimeric repressor is not conserved in other plant species.

\section{Expression of chimeric repressors derived from $D P$ in Pharbitis resulted in a double flower}

To construct double flower of Pharbitis, the chimeric repressor of $D P(D P S R D X)$, which is a homologue of $A G$ in Pharbitis, under the control of the CaMV $35 \mathrm{~S}$ promoter (p35S::DPSRDX), was introduced as a transgene in Pharbitis (Figure 2A). Non-transformant Pharbitis has one pistil and five stamens in a flower bud (Figure 2B). However, the p35S::DPSRDX-introduced callus was difficult to regenerate during transformation, but occasionally a perfect double flower bud showing severe developmental defects was formed, which had a phenotype similar to that of $d p$ mutants (Figure 2C, D). The flower buds were composed of a repeated structure of sepals and petals instead of functional stamens and carpel (Figure 2C, D). The flower buds never developed to the flower opening stage. The $d p$ mutant phenotype is similar to agamous (ag) of Arabidopsis (Yanofsky et al. 1990) and plena (ple) (Bradley et al. 1993) of Antirrhinum (Nitasaka 2003). Both genes encode class-C MADS-box genes and the gene responsible for the $d p$ mutation is also thought to be a member of the class-C MADS-box gene family (Figure 2D). In Pharbitis nil, in the course of cloning the DP gene, cDNA clones containing another C-function MADS-box gene, designated PEONY (PN), were isolated (Nitasaka 2003). The amino acid sequences of DP and PN were compared with those of other C-function MADS-box genes; DP is related to Antirrhinum majus FAR and Arabidopsis AG, and PN is related to Antirrhinum majus PLE (Nitasaka
A
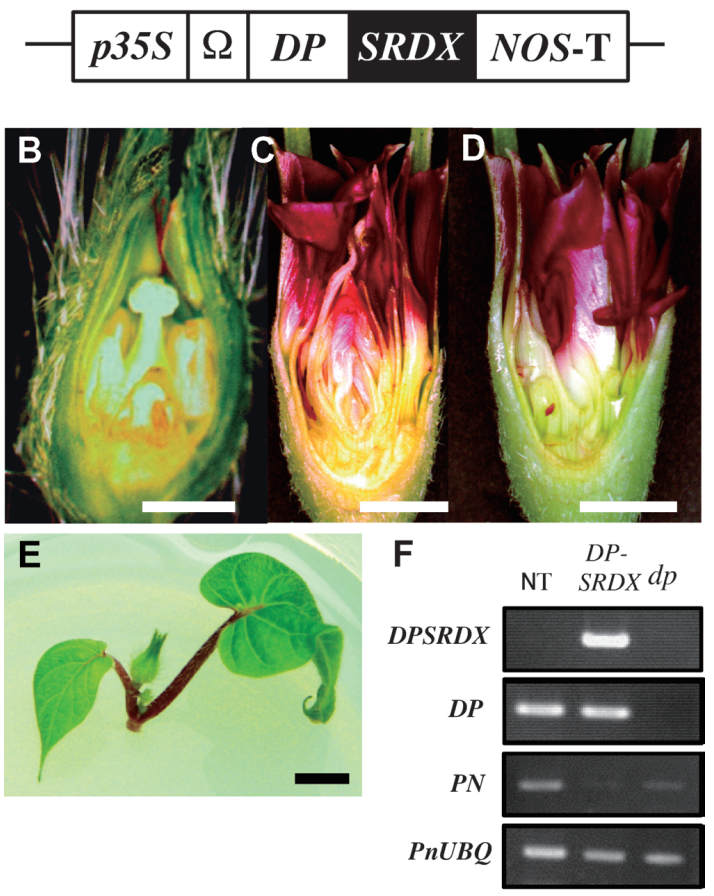

G $\begin{array}{llllllll}\text { R } & H & P & C & A & \text { L } & \text { SE F }\end{array}$

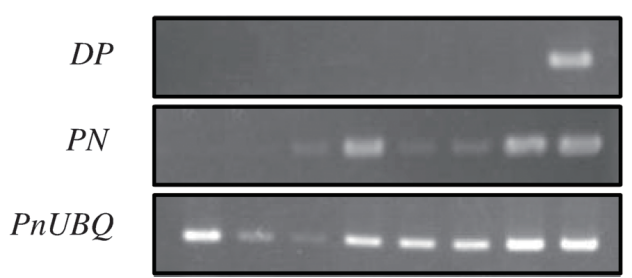

Figure 2. Functional analysis of $p 35 S:: D P S R D X$ in Pharbitis. (A) Schematic representation of the $p 35 S:: D P S R D X$ construct. 35Spro, $\Omega$, $S R D X$, and NOS-T were same as Figure 1. (B) Cross-section of an nontransformant (NT) flower bud. (C) Cross-section of a $p 35 S: \because D P S R D X$ flower bud, in which the stamens and carpel are transformed into petals and a new floral bud, respectively. The inner flower has the same structure. (D) Cross-section of a $d p$ mutant flower bud shows similar structure to $p 35 S:: D P S R D X$. (E) A regenerated $p 35 S:: D P S R D X$ shoot formed on somatic embryo culture. (F, G) Expression analysis by RTPCR. $P n U B Q$ was used as an internal control. (F) Expression of $D P S R D X, D P$, and $P N$ in NT, $p 35 S:: D P S R D X$, and $d p$ mutant. Total RNA was extracted from $1.5-\mathrm{cm}$-long young flower buds of each plant. (G) Expression of $D P$ and $P N$ in NT tissues. Total RNA was extracted from several tissues (R: root, H: hypocotyl, P: petiole, C: cotyledon, A: apical bud) from six-day-old seedlings, leaf (L) from adult plants, somatic embryo (SE) from the transformation process, and flower bud (FB) from adult plants. All scale bars represent $3 \mathrm{~mm}$.

2003). The function of PN is not clear because its mutant is not known, but this gene might have similar functions to FAR (Nitasaka 2003). The p35S::DPSRDX Pharbitis showed severe growth defects and died during regeneration (Figure 2E). We compared the mRNA amount of DPSRDX, DP and $P N$ in floral buds of DPSRDX transgenic Pharbitis and a $d p$ mutant (Figure $2 \mathrm{~F})$. In transgenic DPSRDX plants, $P N$ expression was 
decreased remarkably, as in the $d p$ mutant (Figure $2 \mathrm{~F}$ ). This result indicates that $P N$ might be a target of $D P$, and DPSRDX repressed expression of $P N$ (Figure 2F). To reveal the cause of the growth defects in DPSRDX Pharbitis, we confirmed the expression of internal $D P$ and $P N$ in a variety of organs of NT Pharbitis (Figure $2 \mathrm{G})$. Although $D P$ expression was observed only in floral buds, $P N$ was expressed in the floral bud and various other vegetative organs. From this result, it is likely that $P N$ has a function in vegetative growth in addition to Cfunction in floral buds, ectopic over-expression of $D P S R D X$ resulted in the repression of $P N$ in various other vegetative organs, and growth defects are caused by loss of $P N$.

\section{Construction of inducible repression vectors}

To avoid growth defects in DPSRDX Pharbitis, we used inducible promoters to control the expression of DPSRDX. The GAL4DB transcription factor of yeast was used, and the vectors expressing GAL4DBSRDX by inducible promoters were constructed, as GAL4SRDX represses the overexpression of DPSRDX under control of $p 35 S:: G A L 4$ UAS (Figure 3B, C). We used MultiSite Gateway technology (Invitrogen) for construction of the inducible repression vector. It was developed for the simultaneous cloning of multiple DNA fragments in a versatile format (Cheo et al. 2004; Magnani et al. 2006; Sasaki et al. 2004), and plant binary vectors have been devised for the MultiSite Gateway protocol (Karimi et al. 2005). The functional part of the MultiSite Gateway destination vector $(\mathrm{pKm} 43 \mathrm{GW})$ is the attR4-attR3 cassette, which can recombine with three Gateway donor vectors carrying the appropriate attL sites (Figure 3C) (Karimi et al. 2005). Combined genetic elements $p 35 S$ GALAUAS in pDONR ${ }^{\mathrm{TM}}$ 221-P4-P1r, DPSRDX and Luc in pENTR-D-TOPO, and 35S-T-NOS-T-GAL4SRDXinducible promoter (Alc promoter [ $p A L C]$ or heat-shock promoter $[p H S P))$ in $p D O N R-P 2 r-P 3$ were merged and introduced via a MultiSite LR clonase reaction into a destination vector (pKm43GW) (Karimi et al. 2005), yielding the expression constructs pKmAGD, pKmHGD, pKmAGL and pKmHGL respectively (Figure $3 \mathrm{C}$ ).

A

B Heat shock or EtOH treatment

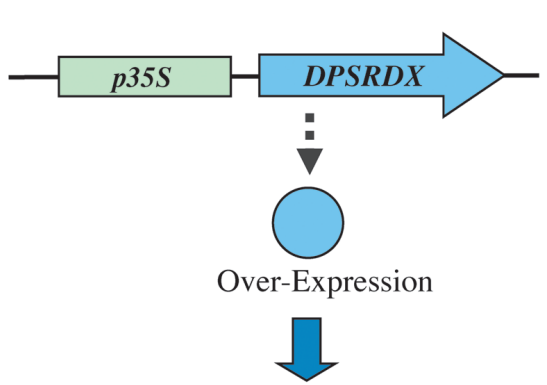

Double flower, Constitutive sterile

(pHSP or pALC)

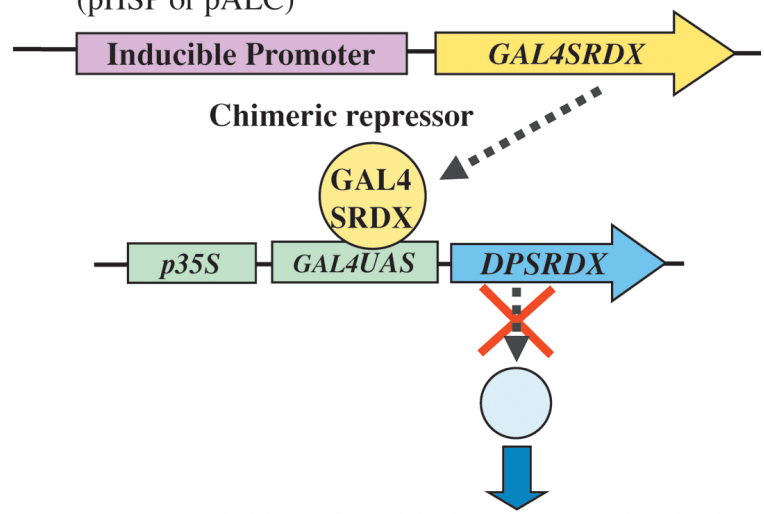

C Alcohol inducible repression vector

Inhibition of double flower, Inductive fertile

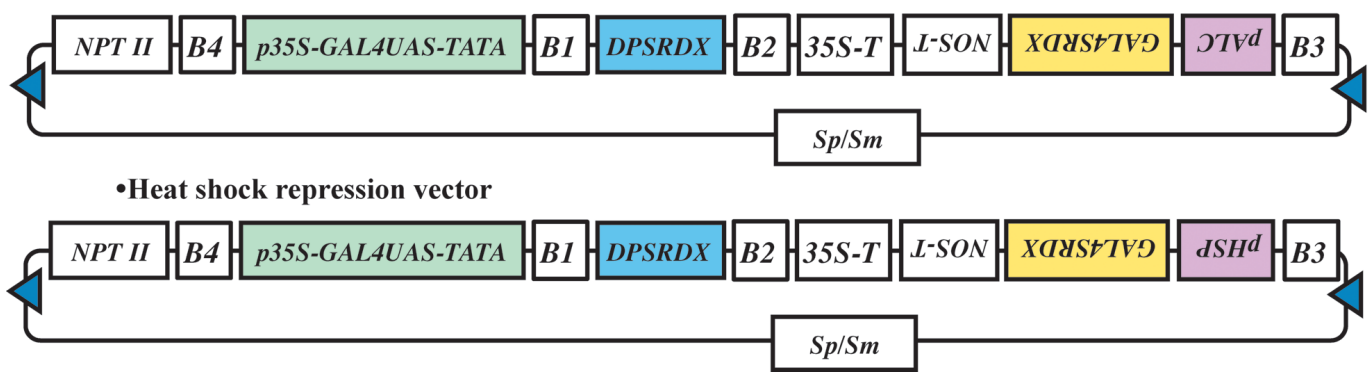

Figure 3. Construction of inducible repression vectors. (A) Schematic diagram of ectopic overexpressing DPSRDX, driven by CaMV 35S promoter. DPSRDX induces double flowers but constitutive sterility. (B) Schematic diagram of repression of overexpressing DPSRDX by inducible expression of GAL4SRDX. GAL4SRDX was driven by the alcohol-inducible promoter system or a heat-shock promoter at a suitable time, that allows inhibition of double flower and inductive fertility. (C) Schematic representation of the Gateway binary expression vectors for alcohol-inducible repression and heat-shock-inducible repression of ectopic overexpression DPSRDX. 35S, GAL4UAS, TATA, GAL4SRDX, Alc Pro, HSP Pro, 35S-T, NOS-T, NPTII, Sp/Sm, represent CaMV35S promoter, GAL4DB binding sequence from yeast, TATA-box the GAL4 DNA-binding domain fused SRDX (repression domain from Arabidopsis SUPERMAN), the alcohol-inducible promoter system (p35S::alcR and pAlcA) from Aspergillus nidulans (Caddick et al. 1998), HSP18.2 promoter from Arabidopsis (Takahashi et al. 1992), CaMV 35S terminator, a nopaline synthase terminator, kanamycin resistance selectable marker, and spectinomycin/streptomycin resistance selectable marker, respectively. 


\section{GAL4SRDX-induced AGD and HGD transgenic plants showed normal growth and double flowers}

We generated transgenic Pharbitis plants with $A G D$ (pALC::GAL4SRDX;p35S:GAL4UAS::DPSRDX) and HGD (pHSP::GAL4SRDX;p35S:GAL4UAS::DPSRDX) designed for inducible repression of DPSRDX or Luc (used as an expression control; $A L$ and $H L$ shown in Table 1) by GAL4SRDX. The $p 35 S:: D P S R D X-$ transformed callus were difficult to regenerate during transgenic steps, as mentioned above, and repression of DPSRDX during regeneration is necessary for regeneration of DPSRDX transgenic Pharbitis. Thus, we investigated the inductive condition during regeneration, because we had no definite information on a suitable inductive condition for Pharbitis with ethanol treatment or heat-shock treatment. At first, in order to confirm $A l c$ promoter system and $H S P$ promoter activity, $A L$ $(p A L C: \because L u c)$ and $H L(p H S P:: L u c)$ and in vitro cultured $\mathrm{T}_{1}$ transgenic callus was used for the luciferase assay. Ethanol vapor treatment is convenient for the culture dish, and Luc activity was detected by ethanol vapor treatment (data not shown). However, long ethanol vapor treatment (overnight or for $1 \mathrm{~h}$ ) caused severe damage to transgenic callus. Thus, we chose ethanol vapor treatment for $30 \mathrm{~min}$. HSP18.2 is a heat-shock inducible natural promoter in Arabidopsis (Takahashi et al. 1992). HSP18.2 promoter activity in Pharbitis was characterized by incubation at a variety of temperatures $\left(33,35,37,39\right.$, or $\left.41^{\circ} \mathrm{C}\right)$ with Luc activity. In Pharbitis, HSP 18.2 promoter activity was hardly detected at 25,33 , 35 , and $37^{\circ} \mathrm{C}$. But was strongly detected at $39^{\circ} \mathrm{C}$ and was less reduced at $41^{\circ} \mathrm{C}$ (data not shown). Therefore, during regeneration, we treated AGD ( $P A L C: \because G A L 4 S R D X$; p35S:GAL4UAS::DPSRDX) transforming cultures with absolute ethanol vapor for $30 \mathrm{~min}$ in the plastic container every two weeks, and HGD (pHSP::GAL4SRDX;p35S: GALAUAS::DPSRDX) transforming cultures with $39^{\circ} \mathrm{C}$ for $2 \mathrm{~h}$ every day, we successfully regenerated $A G D$ and $H G D$ transgenic Pharbitis plants without compromising vegetative growth. Ethanol treatment or heat-shock treatment were effective for regeneration of transformants compared with the non-treated condition. Resultant rate of regeneration in DPSRDX transgenic Pharbitis plants ( $A G D$ and $H G D$ ) was similar to that of the luciferase control transgenic plant ( $A G L$ and $H G L)$ (data not shown).
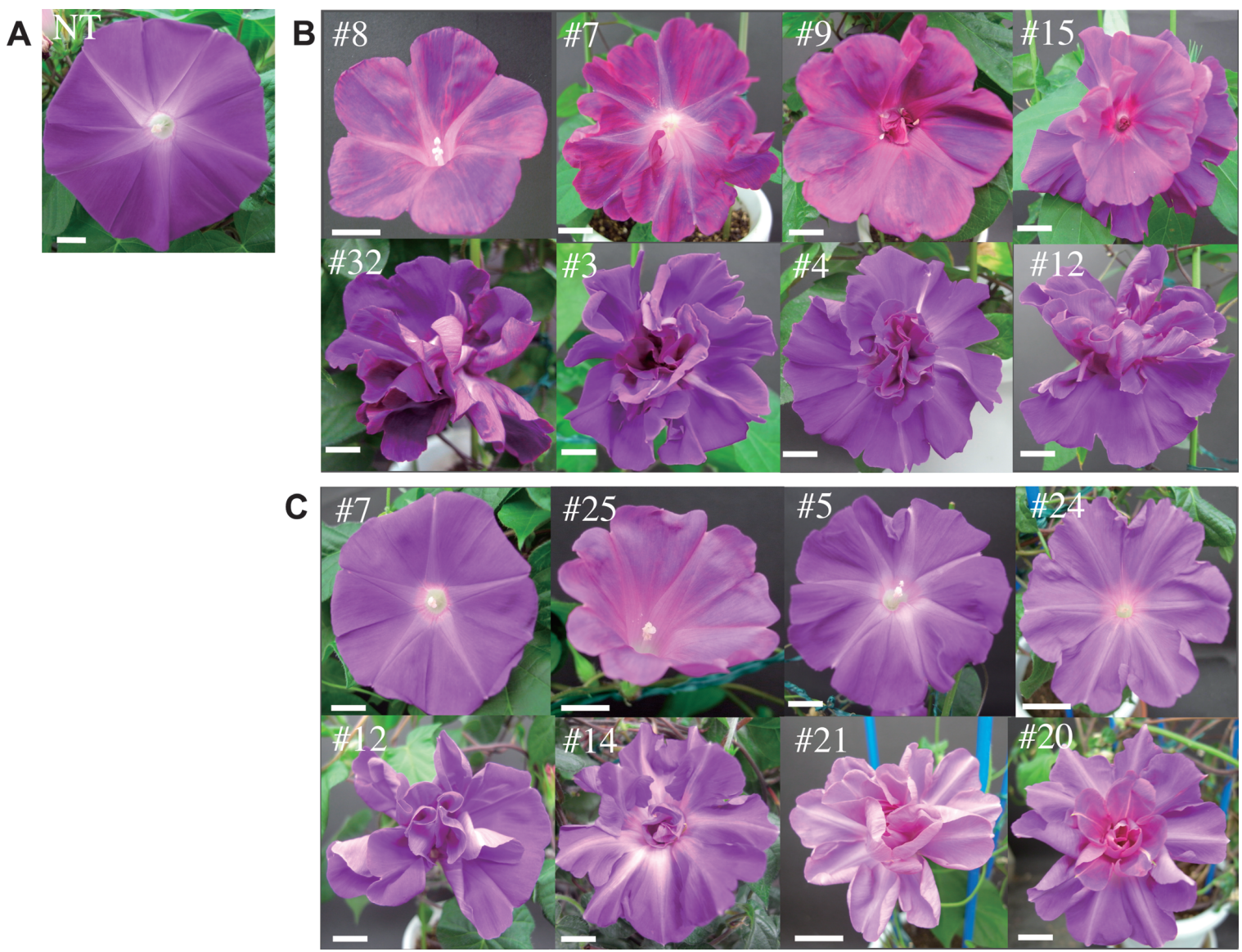

Figure 4. Appearance of DPSRDX induced double flowers. (A) Non-transformant (NT) flower. (B) Flower of $A G D$ (pALC::GAL4SRDX; $35 S: G A L 4 U A S: \because D P S R D X)$. The photographs depict flowers from eight independent $\mathrm{T}_{1}$ transgenic lines. (C) Flower of $H G D$ ( $p H S P:: G A L 4 S R D X ; p 35 S: G A L 4 U A S:: D P S R D X)$. The photographs depict flowers from eight independent $\mathrm{T}_{1}$ transgenic lines. All scale bars represent $1 \mathrm{~cm}$. These photographs are arranged in the order of severity of the phenotype. 
The 58 independent $\mathrm{T}_{1}$ transgenic lines of $A G D$ (pALC::GAL4SRDX;p35S:GAL4UAS::DPSRDX) and the 30 independent $\mathrm{T}_{1}$ transgenic line of HGD (pHSP:: GAL4SRDX;p35S:GAL4UAS::DPSRDX) were examined under normal cultivation conditions. Most of these transgenic plants bore double flowers similar to the ag mutant of Arabidopsis (Yanofsky et al. 1990) and $d p$ mutant of Pharbitis (Nitasaka 2003) (Figure 4B: line $\# 15$, \#32, \#3, \#4, \#12; 4C: \#12, \#14, \#21, \#20). The double flower phenotype was observed in $22.4 \%$ (13 lines) of $A G D$ lines and $43.3 \%$ (13 lines) of $H G D$ lines. The other plants exhibited relatively normal flowers as in NT (Figure 4A) Pharbitis (Figure 4B: \#8, \#7; 4C: \#7, $\# 25$, \#5, \#24). Detailed morphological examination revealed that some of the flowers displayed notched and frilled petals (Figure 4B: \#8, \#7; 4C: \#7, \#25, \#5, \#24). The same floral phenotypic patterns were observed in same transgenic lines, in which weak phenotype lines (Figure 4B: \#8, \#7; 4C: \#7, \#25, \#5, \#24) and strong phenotype lines (Figure 4B: \#15, \#32, \#3, \#4, \#12; 4C: $\# 14, \# 12, \# 21, \# 20)$ were observed. However, intermediate phenotype lines (Figure 4B: \#9) were observed both with NT-like and double flowers. The number of petals was increased in extremely strong phenotype lines (Figure 4B: \#3, \#4, \#12; 4C: \#20, \#21).

\section{Expression level of DPSRDX does not correlate with severity of the phenotype}

To observe the correlation of phenotype with DPSRDX and $P N$ (another class C-function MADS-box gene mentioned above) transcription level, we performed RTPCR on AGD (pALC::GAL4SRDX;p35S:GAL4UAS:: DPSRDX) and HGD (pHSP::GAL4SRDX; $35 S$ : GAL4UAS::DPSRDX) transgenic Pharbitis plants. Expression of DPSRDX was detected in most flower buds of the $A G D$ and $H G D$ transgenic Pharbitis plants (Figure 5A, B). However, the phenotype of $A G D$ lines $\# 3$, \#4, \#12 and \#32 was similar to that of the ag mutant of Arabidopsis (Yanofsky et al. 1990) and $d p$ mutant of Pharbitis (Nitasaka 2003) (Figure 4B), and the DPSRDX expression level was variable. In particular, $A G D$ line \#32 showed a low expression level of DPSRDX (Figure 4B) but bore perfect double flowers. In contrast, $A G D$ line \#7 showed high expression of DPSRDX (Figure 5B) but bore NT-like single flowers (Figure 4B). Similar results were obtained for $H G D$ lines \#12, \#14 and \#20 (Figure 5B), which bore double flowers (Figure 4C). However, DPSRDX expression was not detected in $H G D$ line \#7 (Figure 5B), yet it bore a single-flowered phenotype similar to NT (Figure 4C). Although the transcription level of endogenous $D P$ was unaffected by $D P S R D X, P N$ expression was reduced in the flower buds of $A G D$ transgenic lines \#3, \#4, \#12, and \#32, which resulted in development of double flowers (Figure 5A). $P N$ expression was maintained in NT and line \#7, similar
A NT \#3 \#4 \#12 \#32 \#7

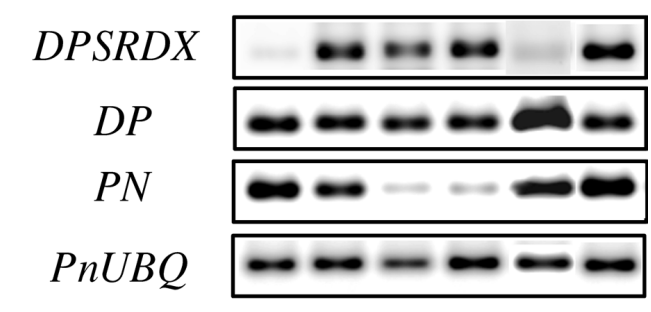

B

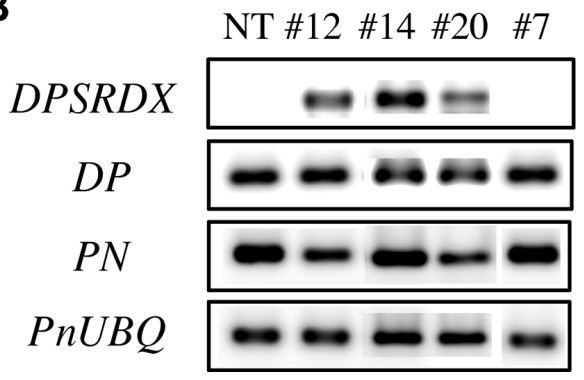

Figure 5. Expression analysis of DPSRDX induced double flowers. Expression of DPSRDX, endogenous DUPULICATED $(D P)$, and $P E O N Y(P N)$ in non-transformant $(\mathrm{NT})$ and $\mathrm{T}_{1}$ transgenic lines (numbers above gel) were determined by RT-PCR. $P n U B Q$ was used as an internal control. (A) Transgeneic plants of $A G D$ (pALC::GAL4SRDX;p35S:GAL4UAS::DPSRDX). (B) Transgeneic plants of HGD (pHSP::GAL4SRDX;35S:GAL4UAS::DPSRDX).

to NT (Figure 5A). Identical results were obtained for $H G D$ transgenic lines \#12, \#14, and \#20 (Figure 5B). Accumulation of $P N$ transcripts showed good correlation with severity of the phenotype.

\section{Repression of overexpressing DPSRDX by alcohol treatment results in a NT-like flower phenotype}

In an attempt to reveal whether GAL4SRDX was induced by ethanol treatment and could repress the overexpressing DPSRDX transcription, we examined the inductive conditions of GALASRDX. AGD ( $p A L C::$ GAL4SRDX; 35 S: GAL4UAS: DPSRDX) transgenic Pharbitis were treated by absolute ethanol vapor, $0.1 \%$ $(\mathrm{v} / \mathrm{v})$ ethanol spray, or $1 \%(\mathrm{v} / \mathrm{v})$ ethanol dipping. Mature plants obtained from five $A G D$-containing Pharbitis lines and a NT were treated with ethanol vapor during $8 \mathrm{~h}$ dark period for two weeks in a $40 \mathrm{~L}$ plastic bag. For vaporous induction, $1.5 \mathrm{ml}$ microcentrifuge tubes filled with absolute ethanol were regularly placed next to the plants in the soil. However, we could not find any phenotypic changes in AGD (pALC::GAL4SRDX;p35S:GAL4UAS:: $D P S R D X)$ transgenic plants in response to ethanol vapor treatment (data not shown). The apical shoot of five $A G D$ Pharbitis lines and a NT (control) was directly sprayed with $0.1 \%(\mathrm{v} / \mathrm{v})$ ethanol. In $A G D$ transgenic line \#4 the double-flowered phenotype was partially repressed (Figure 6B, E, H, K), compared to $A G D$ line \#3 without ethanol treatment (Figure 6A, D, G, J). However, other 


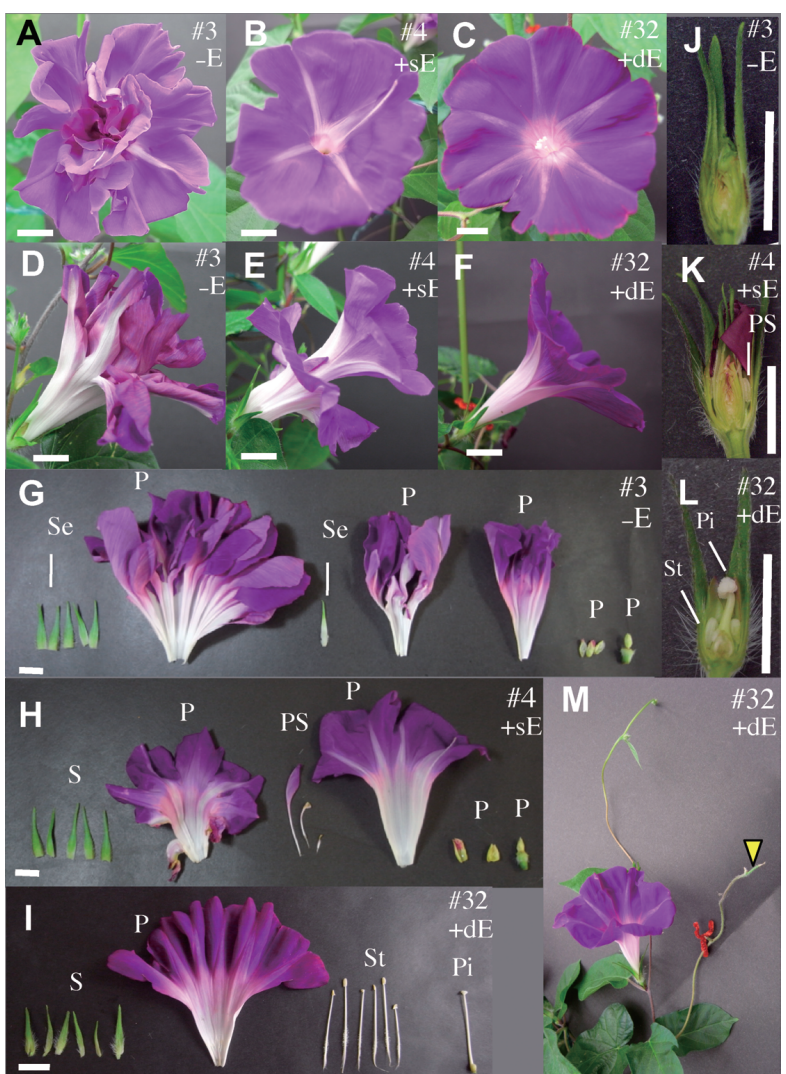

Figure 6. Repression of overexpressing DPSRDX by ethanol treatment resulted in a non-transformant-like flower phenotype. (A, D, G, J) AGD (pALC::GAL4SRDX;p35S:GAL4UAS::DPSRDX) line 3 (\#3) without ethanol treatment (-E). (B, E, H, K) $A G D$ line 4 (\#4) with $0.1 \%$ ethanol spray $(+\mathrm{sE})$. (C, F, I, L) $A G D$ line 32 (\# 32) with $1 \%$ ethanol dipping treatment $(+d E)$. (A, B, C) Face view of the flower. (D, E, F) Side view of the flower. (J, K, L) Cross-section of flower buds. Se: sepal, P: petal, PS: petal-like stamen, St: stamen, Pi: pistil. (G) A mature flower of $A G D \# 3$ dissected into organs. (H) A mature flower of $A G D \# 4$ partially restored reproductive organs with $0.1 \%$ ethanol spray dissected into organs. (I) A mature flower of $A G D \# 32$ restored reproductive organs with $1 \%$ ethanol dipping treatment dissected into organs. (M) AGD\#32 plant one month after ethanol treatment. Arrowhead indicates the shoot subjected to $1 \%$ ethanol dipping treatment $(+d E)$. All scale bars represent $1 \mathrm{~cm}$.

$A G D$ lines showed no typical phenotypic changes in response to $0.1 \%$ ethanol spraying (data not shown). In addition, the shoot tip of mature plants obtained from three $A G D$ lines was dipped in $1 \%(\mathrm{v} / \mathrm{v})$ ethanol solution. As with the ethanol dipping treatment, $A G D$ transgenic line \#32 showed a flower phenotype similar to NT (Figure 6C, F, I, L). The flower of the transgenic plant was composed of six sepals, six petals, six stamens, and one pistil (Figure 6I). One month after ethanol dipping treatment, $A G D$ line \#32 formed a NT-like flower in an axillary bud of the same plant (Figure 6M). The apical bud of the shoot treated with ethanol dipping was killed (Figure 6M).

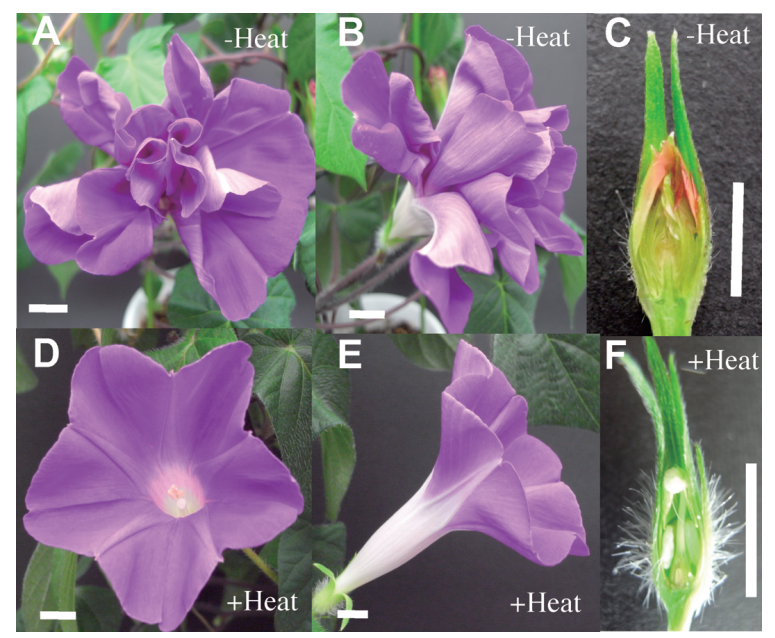

Figure 7. Repression of overexpressing DPSRDX by heat-shock treatment resulted in a non-transformant-like flower phenotype. All photographs represent HGD (pHSP::GAL4SRDX; p35S:GAL4UAS::DPSRDX) line 12 (\#12). (A, B, C) HGD\#12 without heat-shock treatment. (D, E, F) $H G D \# 12$ with heat-shock treatment $\left(39^{\circ} \mathrm{C}\right.$ for $2 \mathrm{~h}$ daily for one month). (A, D) Face view of the flower. (B, E) Side view of the flower. (C, F) Cross-section of flower buds. All scale bars represent $1 \mathrm{~cm}$.

Repression of overexpressing DPSRDX by heatshock treatment results in a NT-like flower phenotype

The HSP18.2 promoter ( $p H S P)$ is strongly activated in all organs of the plant, except in seeds, in response to a shift of temperature to $35-37^{\circ} \mathrm{C}$ in Arabidopsis and $37-38^{\circ} \mathrm{C}$ in Petunia (Takahashi et al. 1992). pHSP::Luc (HL) transgenic Pharbitis were used to determine a suitable heat-shock treatment. Observation of Luc activity of $H L$ transgenic Pharbitis at $33-41^{\circ} \mathrm{C}$ showed that the strongest induction of Luc activity occurred at $39^{\circ} \mathrm{C}$ (data not shown). Thus, HGD\#12 (pHSP:: GAL4SRDX;p35S::GAL4UAS::DPSRDX line 12) and $H G L \# 26$ transgenic $\mathrm{T}_{1}$ lines were exposed to $39^{\circ} \mathrm{C}$ for 2 $\mathrm{h}$ every day for one month. At a normal cultivation temperature $\left(25^{\circ} \mathrm{C}, \mathrm{LD}\right), H G D \# 12$ had completely double flowers (Figure 4C, 7A-C). After heat shock treatment, $H G D \# 12$ produced morphologically NT-like flowers (Figure 7D-F). This result indicates that heatshock-induced GAL4SRDX could repress the doubleflower phenotype by repressing DPSRDX.

\section{Repression of DPSRDX by GAL4SRDX induced pollen formation}

Some flowers of $A G D$ (pALC::GAL4SRDX;p35S:: GALAUAS::DPSRDX) and HGD (pHSP::GAL4SRDX; p35S::GAL4UAS::DPSRDX) plants treated with ethanol or heat-shock produced morphologically NT-like flowers (Figures 6I, L, 7). The $P N$ expression level in a flower bud of $A G D \# 32$ was similar to that of NT (Figure $8 \mathrm{~A}$ ). Moreover, the anther of the $A G D \# 32$ flower contained morphologically normal pollen grains (Figure 8B). 
A

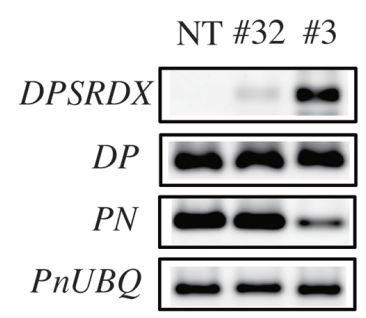

B

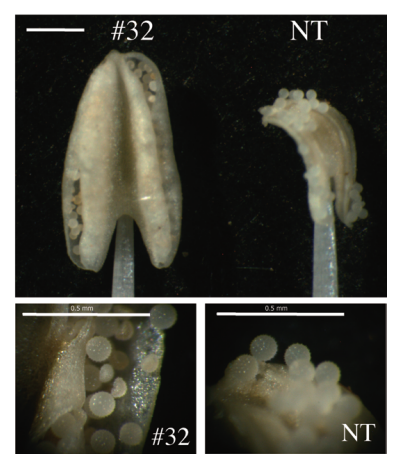

Figure 8. Repression of overexpressing DPSRDX by ethanol treatment restored $P N$ expression and non-transformant (NT)-like flower phenotype with morphologically normal pollen grains. (A) Expression of DPSRDX, endogenous DUPULICATED (DP), and $P E O N Y \quad(P N)$ in young flower buds of NT, $A G D$ (pALC::GAL4SRDX;p35S:GAL4UAS::DPSRDX) line 32 (\#32) and $A G D$ line 3 (\#3) were examined using RT-PCR one month after $1 \%$ ethanol dipping treatment. (B) Comparison of mature anther of a p35S:GAL4UAS::DPSRDX-Alc pro::GAL4SRDX (AGD\#32) plant and NT. No pollen grains were released in $A G D \# 32$. All scale bars represent $0.5 \mathrm{~mm}$.

However, ethanol treatment of $A G D \# 32$ reduced anther dehiscence compared with NT (Figure 8B), and we could not prove that these recovered flowers were fertile.

\section{Discussion}

The CRES-T system is a powerful tool for genetic engineering of horticultural plants, including Torenia fournieri, Chrysanthemum morifolium, Gentiana triflora $\times G$. scabra, Cyclamen persicum, Eustoma grandiflorum, and Pharbitis nil (Mitsuda et al. 2008). However, there are some exceptions to CRES-T system. In Arabidopsis, AGSRDX transgenic plants under the control of the CaMV 35S promoter ( $335 S:: A G S R D X)$ are very similar to those of ag mutants (Mitsuda et al. 2006; Yanofsky et al. 1990). Flowers of the transgenic plants were composed of a repeated structure of sepals instead of functional stamens and a carpel (Mitsuda et al. 2006). In the case of $p 35 S:: A G S R D X$ transgenic Pharbitis plants, independent $\mathrm{T}_{1}$ transgenic lines were similar to the Arabidopsis weak ap3 mutant (MADS-box class-B mutant; Jack et al. 1992), which had extra short green petals and a projecting pistil (Figure 1C, E, F) compared to NT flowers (Figure 1B, D). These results indicate that $A G$ act as a B-function gene in Pharbitis. Although growth defects were observed in $p 35 S:: D P S R D X$ transgenic Pharbitis, occasionally a perfect double flower bud developed. In addition, we also observed that p35S::DPSRDX expressed in Arabidopsis showed a Bfunction mutant-like phenotype (data not shown). These results indicated that the functions of AGSRDX and DPSRDX were converted in Pharbitis and Arabidopsis. Expression analysis showed that ectopic overexpression of AGSRDX resulted in repression of $P n A P 3$ expression in whorl 1 (sepal: Se), but also enhancement of PnPI expression in whorl 4 (pistil: $\mathrm{Pi}$ ) and $D P$ expression in whorl 2 (petal: Pe) (Figure 1I). Although we have no definite information on molecular mechanisms of p35S::AGSRDX expression in Pharbitis, it seems reasonable to suppose that these alterations of gene expression might be involved in the B-function mutantlike phenotype of $p 35 S:: A G S R D X$ in Pharbitis. These results indicated that the chimeric repressor of Arabidopsis is not an 'all-round player' and, in some cases, each plant species requires its own chimeric repressor generated from its own transcription factors.

One other factor is important for utilization of the CRES-T system. Growth defects and decreased fertility are sometimes caused by ectopic overexpression of a chimeric repressor. In this study, we observed growth defects in $p 35 S:: D P S R D X$ transgenic Pharbitis during in vitro culture for regeneration (Figure 2E), and flower buds of $p 35 S:: D P S R D X$ transgenic Pharbitis, similar to the agamous (ag) mutant (Yanofsky et al. 1990) of Arabidopsis and plena (ple) (Bradley et al. 1993) of Antirrhinum. The dupulicated $(d p)$ mutant (Nitasaka 2003) of Pharbitis exhibits a complete transformation of reproductive organs to perianth organs, which results in male- and female-sterile flowers (Figure 2C). Such a drastic floral phenotype renders it difficult or impossible to self-pollinate lines and cross them with other lines for breeding. To solve this problem, there are three approaches: the first is to control the overexpressing transgene using a GAL4SRDX/UAS system driven by inducible promoters; the second is to control expression of the transgene by inducible promoters; and the third is to control expression of the transgene by organ-specific or stage-specific promoters. A GAL4SRDX/UAS system driven by inducible promoters may be advantageous for application in the genetic engineering of floricultural plants, because such a system allows for the control of transgene expression as the need arises; for instance, genetically modified (GM) floricultural potted plants always show the drastic floral phenotype without any treatment whenever they are cultivated by consumers. However, if the suitable natural promoter for transgene expression in the flower is known, we would be a step closer to application of the system for GM floricultural plants. In this case, two further points need to be resolved: improvement of the culture system for vegetative propagation, and selection of a suitable organspecific or stage-specific promoter. Although we are trying to utilize the floral meristem-specific PnAP1 (Pharbitis nil APETALA1) promoter at present, we could not obtain transgenic Pharbitis with perfect double flowers using DPSRDX (data not shown). In addition, we attempted to propagate plants vegetatively by cuttings. A different approach such as tissue culture is needed for 
vegetative propagation.

Therefore, we developed the GAL4SRDX/UAS system driven by inducible promoters (alcohol-inducible and heat-shock promoters) as a new gene-silencing technology for repression of overexpressing transgenes. The EAR-like motif repression domain of SUPERMAN (SRDX) was fused downstream of the coding sequence for the DNA-binding domain of the GAL4 protein (GAL4DB), under the control of the enhancer sequence of the CaMV $35 \mathrm{~S}$ promoter (p35S-GAL4DB-RD) (Hiratsu et al. 2004). Transient assay in Arabidopsis demonstrated that GAL4SRDX repressed expression of the luciferase reporter gene, which was driven by the enhancer sequence of the CaMV $35 \mathrm{~S}$ promoter and five copies of the GAL4 binding site (Hiratsu et al. 2004). We used this GAL4SRDX/UAS system for the construction of a plant binary vector to control the overexpressing transgene.

We used MultiSite Gateway technology (Invitrogen) and constructed the expression clones pKmAGD ( $p A L C:: G A L 4 S R D X ; p 35 S: G A L 4 U A S:: D P S R D X)$, pKmHGD ( $p H S P:: G A L 4 S R D X$; $35 S: G A L 4 U A S:$ : $D P S R D X)$, and the control expression constructs pKmAGL and pKmHGL, which carry the Luc reporter gene. We produced transgenic Pharbitis plants with pKmAGD, pKmHGD, pKmAGL and pKmHGL. In these transgenic plants, DPSRDX or Luc mRNA could be overexpressed constitutively by the CaMV $35 \mathrm{~S}$ promoter without alcohol or heat-shock treatment. Although p35S::DPSRDX transgenic plants did not survive during regeneration, GAL4SRDX induced by alcohol and heatshock treatment made it possible to produce efficiently $D P S R D X$ transgenic plants. Furthermore, AGD ( $p A L C::$ GAL4SRDX; $35 S: G A L 4 U A S: \because D P S R D X)$ and $H G D$ ( $p H S P:: G A L 4 S R D X ; p 35 S: G A L 4 U A S:: D P S R D X$ ) transgenic lines showed a variety of variable flower phenotypes, including double, frilled, and notched-petal flowers (Figure 4). The 58 independent $T_{1}$ transgenic lines of $A G D$ and the 30 independent $\mathrm{T}_{1}$ transgenic line of $H G D$ were examined under normal cultivation conditions; $22.4 \%$ (13 lines) of $A G D$ and $43.3 \%$ (13 lines) of $H G D$ transgenic lines exhibited a repeated structure of sepals and petals instead of functional stamens and carpel, which is a phenotype similar to that of the ag mutant of Arabidopsis (Yanofsky et al. 1990) and $d p$ mutant of Pharbitis (Nitasaka 2003) (Figure 4B: \#15, \#32, \#3, \#4, \#12; 4C: \#12, \#14, \#20,\#21). Although the DPSRDX expression level differed among the lines, the phenotype and $D P$ transcript level were not correlated (Figure 5). In contrast, the $P N$ transcript level showed good correlation with phenotype severity. This indicates that the male- and female-sterile phenotype of the transgenic plants might be unaffected by DPSRDX transcription level, but rather caused by accumulation or activation of DPSRDX, and a candidate target for
DPSRDX might be $P N$. We have no definite information on the chimeric repressor at the protein level, because it is difficult to make specific antibodies for detection of the chimeric repressor, owing to the functional domain of the chimeric repressor (SRDX) consisting of a short amino acid sequence (LDLDLELRLGFA).

We demonstrated control of expression of the transgene $(D P S R D X)$ via a conditional promoter (either an alcohol-inducible or heat-shock-inducible promoter) and GAL4SRDX/UAS system. Transgenic plants that expressed DPSRDX were male and female sterile lacking both male and female organs. To provide a basis for production of hybrid plants in breeding, expression of the transgene, which is related to fertility, must be repressed to recover fertility. In this study, we succeeded in recovering NT-like single flowers with GAL4SRDX induced by alcohol or heat-shock treatment from a part of double-flowered DPSRDX-expressing transgenic plants (AGD\#32, Figure 6C, F, I, L) and HGD\#12, Figure 7D-F). The mRNA accumulation of DPSRDX in AGD\#32 and HGD\#12 transgenic T1 lines were lower than other double-flowered DPSRDX-expressing transgenic lines (Figure 5A, B). Recovering NT-like single flowers of these lines is probably due to low accumulation of DPSRDX mRNA, and it is easy to stop the DPSRDX expression by GAL4SRDX. In order to make practical use of this inducible repression system in breeding, we need to establish suitable inductive conditions for alcohol and heat-shock treatment. In this regard, we are studying Luc activity in different inducible conditions using $A G L, H G L, A L$ and $H L$ transgenic lines. CRES-T is a very effective method for controlling the plant floral phenotype because chimeric repressors can function dominantly to overcome the activity of functionally redundant transcription factors.

It is expected that utilization of the GAL4SRDX/UAS system driven by inducible promoters (alcohol-inducible and heat-shock promoters) could be applied for genetic engineering of horticultural plants. For example, in Arabidopsis thaliana, several families of transcription factors promote adaxial or abaxial cell identity in leaves and other lateral organs. The adaxial-promoting PHABULOSA (PHB), PHAVOLUTA, and REVOLUTA Class II homeodomain/leucine zipper transcription factors (HD-ZIPIIIS) are expressed in the adaxial domain of lateral organs and the central region of the shoot apical meristem. By contrast, members of the abaxialpromoting $K A N A D I$ family (KAN1-3) are expressed in the abaxial domain of organs in a pattern that is complementary to the HD-ZIPIIIS (Emery et al. 2003; Eshed et al. 2001; Kerstetter et al. 2001; McConnell et al. 2001; Otsuga et al. 2001). p35S::PHBSRDX, p35S::KAN1SRDX, p35S::KAN2SRDX transgenic Pharbitis each displayed a valuable floral phenotype (Ono et al. unpublished). However, these transgenic 
Pharbitis also showed a male- and female-sterile phenotype, and thus it is difficult to utilize the plants for breeding. In the case of p35S::PHBSRDX, p35S::KAN1SRDX, and p35S::KAN2SRDX transgenic Pharbitis, an inducible GAL4SRDX gene repression system driven by inducible promoters (alcohol-inducible and heat-shock promoters) might be effective for repression of overexpressing transgenes. Furthermore, establishment of the GAL4SRDX/UAS system allows more profound functional gene analysis by directed expression of the transgene in other species in the future.

\section{Acknowledgements}

We are grateful to Dr. Taku Takahashi (Okayama University) and Dr. Andy Greenland (Syngenta Ltd.) for supplying the heatinducible promoter containing vector pTT101 and the ethanolinducible promoter containing vector binSRNACatN, respectively. We also thank Dr. Eiji Nitasaka (Kyushu University) and the National BioResource Project (NBRP) "Morning glory" by MEXT Japan for supplying seeds of $d p$ mutants, a $D P$ cDNA clone and valuable information on flower mutants in Pharbitis. This work was supported in part by a Grant-in-Aid "Research Project for Utilizing Advanced Technologies in Agriculture, Forestry and Fisheries" from the Research Council, Ministry of Agriculture, Forestry and Fisheries of Japan (grant no. 1782).

\section{References}

Bowman JL, Smyth DR, Meyerowitz, EM (1989) Genes directing flower development in Arabidopsis. Plant Cell 1: 37-52

Bowman JL, Sakai H, Jack T, Weigel D, Mayer U, Meyerowitz, EM (1992) SUPERMAN, a regulator of floral homeotic genes in Arabidopsis. Development 114: 599-615

Brand AH, Perrimon N(1993) Targeted gene expression as a means of altering cell fates and generating dominant phenotypes. Development 118: 401-415

Bradley D, Carpenter R, Sommer H, Hartley N, Coen E (1993) Complementary floral homeotic phenotypes result from opposite orientations of a transposon at the plena locus of Antirrhinum. Cell 72: 85-95

Caddick MX, Greenland AJ, Jepson I, Krause KP, Qu N, Riddell KV, Salter MG, Schuch W, Sonnewald U, Tomsett AB (1998) An ethanol inducible gene switch for plants used to manipulate carbon metabolism. Nat Biotechnol 16: 177-180

Cheo DL, Titus SA, Byrd DR, Hartley JL, Temple GF, Brasch MA (2004) Concerted assembly and cloning of multiple DNA segments using in vitro site-specific recombination: functional analysis of multi-segment expression clones. Genome Res 14: 2111-2120

Coen ES, Meyerowitz EM (1991) The war of the whorls: genetic interactions controlling flower development. Nature 353: 31-37

Coen ES, Romero JM, Doyle S, Elliott R, Murphy G, Carpenter R (1990) floricaula: a homeotic gene required for flower development in Antirrhinum majus. Cell 63: 1311-1322

Davies B, Di Rosa A, Eneva T, Saedler H, Sommer H (1996) Alteration of tobacco floral organ identity by expression of combinations of Antirrhinum MADS-box genes. Plant $J 10$ : 663-677
Eshed Y, Baum SF, Perea JV, Bowman JL (2001). Establishment of polarity in lateral organs of plants. Curr Biol 11: 1251-1260

Emery JF, Floyd SK, Alvarez J, Eshed Y, Hawker NP, Izhaki A, Baum SF, Bowman JL (2003) Radial patterning of Arabidopsis shoots by class III HD-ZIP and KANADI genes. Curr Biol 13: 1768-1774

Felenbok B, Sequeval D, Mathieu M, Sibley S, Gwynne DI, Davies RW (1988) The ethanol regulon in Aspergillus nidulans: characterization and sequence of the positive regulatory gene alcR. Gene 73: 385-396

Fujita Y, Fujita M, Satoh R, Maruyama K, Parvez MM, Seki M, Hiratsu K, Ohme-Takagi M, Shinozaki K, Yamaguchi-Shinozaki $\mathrm{K}$ (2005) AREB1 is a transcription activator of novel ABREdependent ABA signaling that enhances drought stress tolerance in Arabidopsis. Plant Cell 17: 3470-3488

Goto K, Meyerowitz EM (1994) Function and regulation of the Arabidopsis floral homeotic gene PISTILLATA. Genes Dev 8: $1548-1560$

Hiratsu K, Ohta M, Matsui K, Ohme-Takagi M (2002) The SUPERMAN protein is an active repressor whose carboxyterminal repression domain is required for the development of normal flowers. FEBS Lett 514: 351-354

Hiratsu K, Matsui K, Koyama T, Ohme-Takagi M (2003) Dominant repression of target genes by chimeric repressors that include the EAR motif, a repression domain, in Arabidopsis. Plant $J$ 34: 733-739

Hiratsu K, Mitsuda N, Matsui K, Ohme-Takagi M (2004) Identification of the minimal repression domain of SUPERMAN shows that the DLELRL hexapeptide is both necessary and sufficient for repression of transcription in Arabidopsis. Biochem Biophys Res Commun 321: 172-178

Iida S, Hoshino A, Johzuka-Hisatomi Y, Habu Y, Inagaki Y (1999). Floricultural traits and transposable elements in the Japanese and common morning glories. Ann NY Acad Sci 870: 265-274

Iida S, Morita Y, Choi JD, Park KI, Hoshino A (2004) Genetics and epigenetics in flower pigmentation associated with transposable elements in morning glories. Adv Biophys 38: 141-159

Ikeda M, Ohme-Takagi M (2009) A novel group of transcriptional repressors in Arabidopsis. Plant Cell Physiol 50: 970-975

Ikeda M, Mitsuda N, Ohme-Takagi M (2009) Arabidopsis WUSCHEL is a bifunctional transcription factor that acts as a repressor in stem cell regulation and as an activator in floral patterning. Plant Cell 21: 3493-3505

Imai Y (1930) The genetics of Pharbitis Nil. Jpn J Genet 6: $129-131$

Imamura S (1967) Photoperiodic induction and the floral stimulus. In: Imamura S (ed) Physiology of Flowering in Pharbitis nil. Japanese Society of Plant Physiologists, Tokyo, pp 15-28

Jack T, Brockman LL, Meyerowitz EM (1992) The homeotic gene APETALA3 of Arabidopsis thaliana encodes a MADS box and is expressed in petals and stamens. Cell 68: 683-697

Jack T, Fox GL, Meyerowitz EM (1994) Arabidopsis homeotic gene APETALA3 ectopic expression: transcriptional and posttranscriptional regulation determine floral organ identity. Cell 76: 703-716

Johzuka-Hisatomi Y, Hoshino A, Mori T, Habu Y, Iida S (1999) Characterization of the chalcone synthase genes expressed in flowers of the common and Japanese morning glories. Genes Genet Syst 74: 141-147

Karimi M, Meyer BD, Hilson P (2005) Modular cloning in plant cells. Trends Plant Sci 10: 103-105

Karimi M, Bleys A, Vanderhaeghen R, Hilson P (2007) Building 
blocks for plant gene assembly. Plant Physiol 145: 1183-1191

Kerstetter RA, Bollman K, Taylor RA, Bomblies K, Poethig RS (2001). KANADI regulates organ polarity in Arabidopsis. Nature 411: 706-709.

Kikuchi R, Sage-Ono K, Kamada H, Ono M (2005) Efficient transformation mediated by Agrobacterium tumefaciens with a ternary plasmid in Pharbitis nil. Plant Biotechnol 22: 295-302

Koyama T, Furutani M, Tasaka M, Ohme-Takagi M (2007) TCP transcription factors control the morphology of shoot lateral organs via negative regulation of the expression of boundaryspecific genes in Arabidopsis. Plant Cell 19: 473-484

Laughon A, Gesteland RF (1984) Primary structure of the Saccharomyces cerevisiae GAL4 gene. Mol Cell Biol 4: 260267

Magnani E, Bartling L, Hake S (2006) From Gateway to MultiSite Gateway in one recombination event. BMC Mol Biol 7: 46

Mandel MA, Gustafson-Brown C, Savidge B, Yanofsky MF (1992) Molecular characterization of the Arabidopsis floral homeotic gene APETALA1. Nature 360: 273-277

Masclaux F, Charpenteau M, Takahashi T, Pont-Lezica R, Galaud JP (2004) Gene silencing using a heat-inducible RNAi system in Arabidopsis. Biochem Biophys Res Commun 321: 364-369

Matsuhara S, Jingu F, Takahashi T, Komeda Y (2000) Heat-shock tagging: a simple method for expression and isolation of plant genome DNA flanked by T-DNA insertions. Plant $J$ 22: 79-86

Matsui K, Tanaka H, Ohme-Takagi M (2004) Suppression of the biosynthesis of proanthocyanidin in Arabidopsis by a chimeric PAP1 repressor. Plant Biotechnol J 2: 487-493

Matsui K, Hiratsu K, Koyama T, Tanaka H, Ohme-Takagi M (2005) A chimeric AtMYB23 repressor induces hairy roots, elongation of leaves and stems, and inhibition of the deposition of mucilage on seed coats in Arabidopsis. Plant Cell Physiol 46: 147-155

McConnell JR, Emery J, Eshed Y, Bao N, Bowman J, Barton MK (2001) Role of PHABULOSA and PHAVOLUTA in determining radial patterning in shoots. Nature 411: 709-713

Mitsuda N, Seki M, Shinozaki K, Ohme-Takagi M (2005) The NAC transcription factors NST1 and NST2 of Arabidopsis regulate secondary wall thickenings and are required for anther dehiscence. Plant Cell 17: 2993-3006

Mitsuda N, Hiratsu K, Todaka D, Nakashima K, YamaguchiShinozaki K, Ohme-Takagi M (2006) Efficient production of male and female sterile plants by expression of a chimeric repressor in Arabidopsis and rice. Plant Biotechnol J 4: 325-332

Mitsuda N, Umemura Y, Ikeda M, Shikata M, Koyama T, Matsui K, Narumi T, Aida R, Sasaki K, Hiyama S, et al. (2008) FioreDB: a database of phenotypic information induced by the chimeric repressor silencing technology (CRES-T) in Arabidopsis and floricultural plants. Plant Biotechnol 25: 37-43

Nakai M, Goto A, Nohara T, Sugita D, Endo T (1994) Identification of the SecA protein homolog in pea chloroplasts and its possible involvement in thylakoidal protein transport. J Biol Chem 269: $31338-31341$

Narumi T, Aida R, Niki T, Nishijima T, Mitsuda N, Hiratsu K, Ohme-Takagi M, Ohtsubo N (2008) Chimeric AGAMOUS repressor induces serrated petal phenotype in Torenia fournieri similar to that induced by cytokinin application. Plant
Biotechnol 25: 45-53

Nitasaka E (2003) Insertion of an En/Spm-related transposable element into a floral homeotic gene DUPLICATED causes a double flower phenotype in the Japanese morning glory. Plant $J$ 36: $522-531$

Ohta M, Matsui K, Hiratsu K, Shinshi H, Ohme-Takagi M (2001) Repression domains of class II ERF transcriptional repressors share an essential motif for active repression. Plant Cell 13: 1959-1968

Otsuga D, DeGuzman B, Prigge MJ, Drews GN, Clark SE (2001) REVOLUTA regulates meristem initiation at lateral positions. Plant J 25: 223-236

Pateman JA, Doy CH, Olsen JE, Norris U, Creaser EH, Hynes M (1983) Regulation of alcohol dehydrogenase (ADH) and aldehyde dehydrogenase (AldDH) in Aspergillus nidulans. Proc $R$ Soc Lond B Biol Sci 217: 243-264

Riechmann JL, Heard J, Martin G, Reuber L, Jiang C, Keddie J, Adam L, Pineda O, Ratcliffe OJ, Samaha RR, et al. (2000) Arabidopsis transcription factors: genome-wide comparative analysis among eukaryotes. Science 290: 2105-2110

Rual JF, Hirozane-Kishikawa T, Hao T, Bertin N, Li S, Dricot A, Li N, Rosenberg J, Lamesch P, Vidalain PO, et al. (2004) Human ORFeome version 1.1: a platform for reverse proteomics. Genome Res 14: 2128-2135

Sasaki Y, Sone T, Yoshida S, Yahata K, Hotta J, Chesnut JD, Honda T, Imamoto F (2004) Evidence for high specificity and efficiency of multiple recombination signals in mixed DNA cloning by the Multisite Gateway system. J Biotechnol 107: 233-243

Sealy-Lewis H, Lockington R (1984) Regulation of two alcohol dehydrogenases in Aspergillus nidulans. Curr Genet 8: 253-259

Shikata M, Ohme-Takagi M (2008) The utility of transcription factors for manipulation of floral trait. Plant Biotechnol 25: $31-36$

Sommer H, Beltran JP, Huijser P, Pape H, Lonnig WE, Saedler H, Schwarz-Sommer Z (1990) Deficiens, a homeotic gene involved in the control of flower morphogenesis in Antirrhinum majus: the protein shows homology to transcription factors. EMBO J 9: 605-613

Takahashi T, Naito S, Komeda Y (1992) Isolation and analysis of the expression of two genes for the 81-kilodalton heat-shock proteins from Arabidopsis. Plant Physiol 99: 383-390

Tohge T, Matsui K, Ohme-Takagi M, Yamazaki M, Saito K (2005) Enhanced radical scavenging activity of genetically modified Arabidopsis seeds. Biotechnol Lett 27: 297-303

Trobner W, Ramirez L, Motte P, Hue I, Huijser P, Lonnig WE, Saedler H, Sommer H, Schwarz-Sommer Z (1992) GLOBOSA: a homeotic gene which interacts with DEFICIENS in the control of Antirrhinum floral organogenesis. EMBO J 11: 4693-4704

Yanofsky MF, Ma H, Bowman JL, Drews GN, Feldmann KA, Meyerowitz EM (1990) The protein encoded by the Arabidopsis homeotic gene agamous resembles transcription factors. Nature 346: 35-39

Vince-Prue D, Gressel J (1985) Pharbitis nil. In: Halevy AH (ed) Handbook of Flowering. Vol IV. CRC press, Boca Raton, Florida, pp 47-81 